\title{
Too many eggs in the Asia-Pacific basket
}

The decision by Australia not to fund the European Southern Observatory is a sign that its politicians see its future in science as lying in the Asia-Pacific region. That conclusion is premature.

LAST week's long-awaited "innovation statement" from the Australian Prime Minister, Paul Keating (see page 653), had one glaring and embarrassing omission: an expected contribution of A $\$ 28$ million to the European Southern Observatory in Chile. It is to be hoped that the sudden decision to drop funding for the observatory was not taken lightly, given that it was strongly backed by the Australian scientific community, including the Academy of Sciences.

Senator Peter Cook, the minister of industry, science and technology, is no doubt embarrassed by that knowledge, and probably not a little piqued at having had the presentational initiative for what is really his innovation statement snatched away by the prime minister. And only a week before the statement was made, Cook told the audience at a Nature-sponsored conference in Canberra that "science enhances our international prestige and image". One way to enhance his country's image is surely to make a significant (and long anticipated) contribution to the European observatory, including state-of-the-art Australian telescope technology and Australian astronomical brain-power.

One reason for Keating's decision is probably mundane. He wants to get re-elected, and he no doubt thinks he has a better chance if Australia funds several smaller research facilities in every major city than by putting significant funds into a European facility in Chile. That is not to say that the seven facilities chosen are not worthy of funding. At least one of them, the Proteome Analysis Centre in Sydney, is scientifically daring and may achieve a significant presence on the world stage. But the decision to drop support for the observatory is contrary to the scientific advice he has been given.

A more interesting and debatable implication of Keating's decision is that he and his cabinet see Australia's future collaborations in science as lying primarily in the Asia-Pacific region rather than in Europe. Keating's innovation statement was peppered with references to the Asia-Pacific Economic Forum (APEC), which has recently held its first two big meetings on science and technology in Beijing and Taipei. And the only major research facility announced last week to involve use of facilities overseas is the Synchrotron Research Programme, which has a beamline at the Photon Factory in Japan, as well as the Advanced Photon Source at the Argonne National Laboratory in the United States (also a member of APEC).

Certainly there seems to be plenty of money in Australia for scientists and science policy-makers to shuttle back and forth across the Pacific to Asia. But how substantial are Australia's links in science with its Asian neighbours and how substantial are they likely to become? The beamline at the photon factory in Tsukuba Science City is tucked away at position 31 in the corner of Japan's synchrotron facility, and has yet to make its mark on world science. And there are certainly not large numbers of Australian scientists taking up long-term residence in Japan - nor are there likely to be. The language barrier is significant and the amount of support (both money and manpower) for basic research in Japan's universities is still miserly, despite recent efforts by Japanese politicians to legislate more support for basic research.

There are state-of-the-art third-generation synchrotrons in South Korea and Taiwan that sit half empty for lack of users. But
Australians are not rushing to use them, despite the fact that Australia has already sent a delegation to the South Korean facility.

What of China? There are pockets of activity there in basic research that have sprung up in the past decade of a competitive market economy, and China may well surpass its neighbour Japan in some areas of science within a few years because of its government's more inventive management of science. But again it seems unlikely that the environment will be attractive enough to lead to substantive links in science with Australia.

The bottom line is that although the economies of Asia appear to be booming, the centre of gravity of basic research still rests very much in the West between the United States and Europe. Many Australian scientists have their roots there and it is defying the realities to think that attention can be swung to the Asia-Pacific region overnight.

At the Nature-sponsored conference in Canberra, Eugene Wong of the Hong Kong University of Science and Technology, a former associate director of the White House Office of Science and Technology Policy in the United States, argued that those Western economies, such as the United States, that have invested heavily in basic research obtain the best returns on more general public investment in terms of growth of the economy. Asia-Pacific economies may be booming, but sustaining such growth requires huge and inefficient reinvestment because of their lack of a science base, says Wong.

Keating may have won a few votes with his statement last week. But it reveals an inadequate appreciation of where, realistically, the best international interests of Australia's science still lie.

\section{Postscript from a new hand}

Although Nature is about to enter a period of change, its values are not.

IN last week's issue, my predecessor (“an old hand") signed off. In his valedictory leading article, John Maddox thanked "a host of readers and contributors for correspondence that has always been illuminating and often entertaining". It would be inappropriate for me to attempt an overall assessment of his formidable achievements as Editor of Nature, but illumination and entertainment have undoubtedly been among them. Nor do I intend to outline specific plans for the future - changes are under way, but new developments are often best left to announce themselves.

Changes in style are certain, however, as is the appearance of new kinds of content. Resources are being invested in enhancing further the readability of what we produce. And there are core strengths that readers can continue to be sure of: the calibre of our authorship in "the front half", for example, and the very considerable talent and man-hours applied so as to combine speedy turnaround with properly considered decision making across all the disciplines published in "the back half". Above all, Nature, an entity much more significant than any individual Editor, will continue to pursue scientific excellence and journalistic impact with vigorous independence.

Philip Campbell 